\title{
Recognition and management of respiratory co-infection and secondary bacterial pneumonia in patients with COVID-19
}

\section{ABSTRACT}

In COVID-19, respiratory infection with SARS-CoV-2 plus another virus (viral co-infection) or with SARS-CoV-2 plus a bacterial pathogen (combined viral and bacterial pneumonia) has been described. Secondary bacterial pneumonia can follow the initial phase of viral respiratory infection or occur during the recovery phase. No obvious pattern or guidelines exist for viral co-infection, combined viral and bacterial pneumonia, or secondary bacterial pneumonia in COVID-19. Based on existing clinical data and experience with similar viruses such as influenza and SARS-CoV, the management approach in COVID-19 should, ideally, take into consideration the overall presentation and the trajectory of illness.

\section{KEY POINTS}

All patients presenting with symptoms of respiratory infection should undergo testing for influenza with a polymerase chain reaction assay in addition to SARSCoV-2 testing.

Guideline-driven empiric antibiotic use may be reasonable until secondary bacterial infection is ruled out.

The duration of antibacterial therapy is generally 5 to 7 days for community-acquired pneumonia and 7 days for hospitalacquired pneumonia and ventilator-associated pneumonia.

The authors report no relevant financial relationships which, in the context of their contributions, could be perceived as a potential conflict of interest.

doi:10.3949/ccjm.87a.ccc015
TVEn as severe acute respiratory syndrome Coronavirus type-2 (SARS-CoV-2), the etiological agent of coronavirus disease 2019 (COVID-19), spreads across the globe, the pathophysiology of the disease remains incompletely understood. Respiratory infection caused by more than one viral pathogen (viral co-infection) or by both viral and bacterial pathogens (combined viral and bacterial pneumonia) has been well described. Secondary bacterial pneumonia can follow the initial phase of viral respiratory infection or can occur during the recovery phase. ${ }^{1}$ Data on SARS-CoV-2 are limited, but thus far, the overall incidence of viral co-infection has varied widely from $0 \%$ to $19 \%$ in different case series, ${ }^{2-7}$ and combined viral and bacterial pneumonia rates appear to be low., ${ }^{3,8-10}$ There is also a dearth of data on the predisposing factors and causative organisms.

Combined viral and bacterial pneumonia and secondary bacterial pneumonia by Staphylococcus aureus and other common communityacquired pneumonia pathogens have been best studied in seasonal ${ }^{2}$ and pandemic ${ }^{2,3}$ influenza and contribute significantly to morbidity and mortality. In the earlier pandemic of severe acute respiratory syndrome (SARS), secondary bacterial pneumonia occurred as ventilatorassociated pneumonia in $25 \%$ of patients at a single center; methicillin-resistant $S$ aureus (MRSA) was the causative organism in $47 \%$ of cases, although there was significant concern for cross-transmission. ${ }^{7}$

Because no obvious pattern or guidelines 
exist for viral co-infection, combined viral and bacterial pneumonia, or secondary bacterial pneumonia in the context of SARSCoV-2, the following commentary is based on existing clinical data and experience with similar viruses such as influenza and SARSCoV. With what we know so far, the approach in the context of COVID-19 would, ideally, take into consideration the overall presentation as well as the trajectory of illness.

\section{VIRAL CO-INFECTION}

All patients presenting with symptoms of respiratory infection should be tested for influenza with a polymerase chain reaction (PCR) assay in addition to SARS-CoV-2. PCR assays can also be performed for other respiratory viruses if available.

Regardless of disease severity, all patients with influenza $A$ or B viral co-infection should be treated with oseltamivir or an alternative agent. ${ }^{11}$ Empiric treatment for influenza viral co-infection can be considered while waiting for test results if an obvious exposure or risk factor is present. If viral co-infection with another respiratory virus such as respiratory syncytial virus is identified, treatment options are limited and effective only in spe-

Management should take into consideration the overall presentation and trajectory of illness cific scenarios such as immunosuppression or hypogammaglobulinemia. ${ }^{12,13}$ Infectious disease consultation is strongly recommended to determine the benefits of such treatment in light of the potential risk for exacerbating COVID-19-related organ failure and the potential adverse effects of the medication or medications.

\section{BACTERIAL PNEUMONIA}

Recognizing combined viral and bacterial pneumonia or secondary bacterial pneumonia with COVID-19 requires a high index of suspicion. Some characteristics of bacterial infection may still be identifiable despite a significant overlap of viral and bacterial symptomatology (Table 1). ${ }^{2-10,14-29}$ Neutrophilic leukocytosis is the hallmark of bacterial pneumonia, whereas COVID-19 patients typically present with a normal white blood cell count with lymphopenia., ${ }^{5,8,14,15}$

Procalcitonin is neither sensitive nor specific in differentiating the etiology of commu- nity-acquired pneumonia. ${ }^{11}$ However, several series of COVID-19 cases have consistently reported normal (low) procalcitonin levels in isolated SARS-CoV-2 infection, leading to its widespread, albeit unvalidated, use to "rule out" combined viral and bacterial pneumonia, although the exact cutoff remains to be determined. This observation highlights the need to consider all variables in the context of the clinical scenario.

In patients with mild to moderate respiratory failure consistent with the presentation of COVID-19 and without obvious signs of bacterial infection, the likelihood of combined viral and bacterial pneumonia is low, and antibiotics can be safely held off. In this case, gradually worsening respiratory failure within the first week of presentation is more likely to be from progression of COVID-19 than from a new superimposed secondary bacterial pneumonia. This includes patients who are started on noninvasive forms of supplemental oxygen support and then ultimately require invasive mechanical ventilation.

In the absence of supporting evidence of bacterial pneumonia, antibiotics should not be initiated even if respiratory distress is progressing. However, if a patient develops new or acutely worsening respiratory failure, sepsis, or both after an initial phase of consistent improvement (considered to be days), then nosocomial acquisition of secondary bacterial infection is likely unless proven otherwise, ie, secondary bacterial pneumonia in the form of hospital-acquired pneumonia, infection at an extrapulmonary site, or both.

While COVID-19 by itself can cause acute respiratory decompensation, data regarding secondary bacterial pneumonia playing a role in such decompensation are limited. Therefore, guideline-driven empiric antibiotic use may be reasonable until this secondary infection is ruled out. Supportive evidence for secondary bacterial pneumonia includes one or more of the following: new or recrudescent fever; new onset or change in the character of sputum; new leukocytosis or new neutrophilia (or both); new relevant imaging findings; and new or increasing oxygen requirements. It is also important to consider all other sources of hospital-acquired infections in these patients, such as indwelling central venous catheters or 
urinary tract catheters, and treat them accordingly.

For a critically ill patient admitted with severe respiratory failure, empiric treatment for all possible causes up front is essential. This is especially important because procalcitonin levels can be falsely elevated in patients with multiorgan failure, ${ }^{30,31}$ and imaging studies may be limited in differentiating bilateral infiltrates of acute respiratory distress syndrome from obscured consolidation of bacterial infection.

Empiric therapy for community-acquired pneumonia should be based on the guidelines of the Infectious Diseases Society of America (IDSA) and the American Thoracic Society (ATS), as well as on host risk factors and prior microbiologic data. ${ }^{19}$ Respiratory samples (tracheal aspirate in mechanically ventilated patients is preferable to sputum) and blood cultures should be sent for all patients, ideally before antibiotics have been started. Streptococcus pneumoniae urine antigen should be tested in all patients presenting with severe community-acquired pneumonia. Legionella pneumophila urine antigen and Mycoplasma pneumoniae IgM and IgG antibodies can be sent based on clinical context and epidemiology.

In the absence of signs of bacterial pneumonia, a positive respiratory culture can represent colonization, especially in those with prior pneumonia with the same organism or altered airway anatomy. Laboratory markers, radiologic features (see Table 1 and above), and quantitative and semiquantitative culture methods can help in making this distinction. ${ }^{19}$

Secondary bacterial pneumonia in a patient on invasive mechanical ventilation has a presentation similar to that of hospital-acquired pneumonia but warrants aggressive use of empiric broad-spectrum antibiotics with coverage for MRSA, Pseudomonas aeruginosa, and possibly other multidrug-resistant organisms in accordance with the guidelines. ${ }^{19}$ It is also important to consider the side effects of antibiotics and institutional antibiograms.

Patients with ventilator-associated tracheobronchitis often lack the classic signs of secondary bacterial pneumonia, may have increased secretions and low-grade fevers, and can be difficult to wean from ventilatory support. The
TABLE 1

\section{Key points for laboratory and imaging findings}

\section{Co-infection and secondary bacterial infection}

Viral co-infection incidence varies in different case series $(0 \%-19 \%)^{2-7,29}$

Combined bacterial and viral infection is rare in COVID-19 patients $3,8-10$

Secondary bacterial infection is not uncommon and leads to significant morbidity and mortality, especially in the elderly ${ }^{49,16}$

\section{Procalcitonin}

Detectable in 2 to 4 hours, peaks at 12 to 24 hours, and has a half-life of 25 to 30 hours

Levels are normal $(<0.5 \mu \mathrm{g} / \mathrm{L})$ in COVID-19 patients with mild disease and may be elevated $(\geq 0.5 \mu \mathrm{g} / \mathrm{L})$ in patients with severe disease $\mathrm{e}^{10,14}$

Elevated levels correlate with a nearly 5 -fold higher risk of severe SARS-CoV-2 infection ${ }^{17}$

Elevated levels are not specific to bacterial infection because they can also be raised in patients with acute respiratory distress syndrome, end-stage renal disease, cardiogenic shock, and multiorgan failure ${ }^{18}$

A normal level makes bacterial infection less likely and can guide antibiotic discontinuation ${ }^{19,20}$

In bacterial infection, levels may be less affected by IL-6 inhibitors than is C-reactive protein (CRP) ${ }^{21-23}$

\section{CRP, erythrocyte sedimentation rate (ESR)}

CRP and ESR are nonspecific inflammatory markers. Both are generally elevated in COVID-19 and are therefore not helpful in differentiating it from bacterial infection

Tocilizumab rapidly reduces CRP and leukocytosis and may suppress fever ${ }^{24-26}$

\section{Typical radiographic features of COVID-19}

Chest radiography: bilateral, peripheral, lower-zone predominant air-space disease ${ }^{27}$

Computed tomography: bilateral, predominantly peripheral groundglass opacities, crazy paving, and consolidation ${ }^{28}$; findings vary based on stage or phase of the disease

\section{Typical radiographic features of bacterial pneumonia}

Chest radiography: lobar or segmental air-space opacification \pm air bronchograms

Computed tomography: segmental or lobar focal dense consolidation with or without ground-glass opacities 
evidence to support antibacterial therapy for this clinical entity is limited and warrants a judicious case-based analysis.

The duration of antibacterial therapy is generally 5 to 7 days for community-acquired pneumonia $^{32}$ and 7 days for hospital-acquired pneumonia and ventilator-associated pneumonia $^{19}$ in the absence of complications. Consider shortening the duration if patients demonstrate signs of clinical stabilization, especially if adverse effects are seen. Checking the procalcitonin level at presentation will help in the de-escalation of antibiotics based on the trend of procalcitonin levels in 24 to 48 hours. ${ }^{33}$ If a microbiological source is not identified within 48 hours of testing and the procalcitonin level is less than $0.5 \mu \mathrm{g} / \mathrm{L}$ or decreases by $80 \%$ or more from peak concentration, it is reasonable to discontinue all antibiotics. ${ }^{19}$

The use of interleukin 6 (IL-6) inhibitors such as tocilizumab for COVID-19-related cytokine activation syndrome presents a unique challenge because they suppress common signs of sepsis. The risk of serious bacterial infections has been consistently reported to be higher with tocilizumab use for rheumatologic diseases. ${ }^{34-37}$ C-reactive protein and other acute-phase reactants including white blood cell count may be unreliable acutephase reactants and may not rise in response to a secondary bacterial infection after tocilizumab use. ${ }^{35,38,39}$ Exactly how long this effect lasts with 1 or 2 doses is unclear. Procalcitonin may be less affected by IL-6 inhibitors, ${ }^{21-23}$ but the data to differentiate bacteria from viral pneumonia in this context are limited and should be further evaluated.

Lastly, invasive pulmonary aspergillosis has been described in critically ill patients with seasonal ${ }^{40,41}$ and pandemic ${ }^{42}$ influenza and is associated with high morbidity and mortality rates. Invasive pulmonary aspergillosis was also reported in patients with COVID-19-associated acute respiratory distress syndrome. ${ }^{43}$ This complication should be considered in high-risk patients such as those with immunecompromising conditions, precedent or concomitant influenza viral co-infection, clinical deterioration despite appropriate antibiotics, and positive fungal markers such as galactomannan on culture. If invasive pulmonary aspergillosis is suspected, treatment with a broad antifungal such as voriconazole should be initiated promptly in consultation with infectious disease colleagues.

\section{REFERENCES}

1. van der Sluijs KF, van der Poll T, Lutter R, Juffermans NP, Schultz MJ. Bench-to-bedside review: bacterial pneumonia with influenzapathogenesis and clinical implications. Crit Care 2010; 14(2):219. doi:10.1186/cc8893

2. Pongpirul WA, Mott JA, Woodring JV, et al. Clinical characteristics of patients hospitalized with coronavirus disease, Thailand. Emerg Infect Dis 2020; 26(7):1580-1585. doi:10.3201/eid2607.200598

3. Arentz M, Yim E, Klaff L, et al. Characteristics and outcomes of 21 critically ill patients with COVID-19 in Washington State. JAMA 2020; 323(16):1612-1614. doi:10.1001/jama.2020.4326

4. Wu C, Chen X, Cai Y, et al. Risk factors associated with acute respiratory distress syndrome and death in patients with coronavirus disease 2019 pneumonia in Wuhan, China. JAMA Intern Med 2020; 180(7):1-11. doi:10.1001/jamainternmed.2020.0994

5. Ding Q, Lu P, Fan Y, Xia Y, Liu M. The clinical characteristics of pneumonia patients coinfected with 2019 novel coronavirus and influenza virus in Wuhan, China. J Med Virol 2020; Mar 20. doi:10.1002/jmv.25781

6. Khodamoradi Z, Moghadami M, Lotfi M. Co-infection of coronavirus disease 2019 and influenza a: a report from Iran. Arch Iran Med 2020; 23(4):239-243. doi:10.34172/aim.2020.04

7. Touzard-Romo F, Tapé C, Lonks JR. Co-infection with SARS-CoV-2 and human metapneumovirus. R I Med J (2013) 2020; 103(2):75-76. pmid:32192233

8. Chen N, Zhou M, Dong X, et al. Epidemiological and clinical characteristics of 99 cases of 2019 novel coronavirus pneumonia in Wuhan, China: a descriptive study. Lancet 2020; 395(10223):507-513. doi:10.1016/S0140-6736(20)30211-7

9. Wang L, He W, Yu X, et al. Coronavirus disease 2019 in elderly patients: characteristics and prognostic factors based on 4-week follow-up. J Infect 2020; Mar 30. doi:10.1016/j.jinf.2020.03.019

10. Zhou F, Yu T, Du R, et al. Clinical course and risk factors for mortality of adult inpatients with COVID-19 in Wuhan, China: a retrospective cohort study. Lancet 2020; 395(10229):1054-1062. doi:10.1016/S0140-6736(20)30566-3

11. Uyeki TM, Bernstein HH, Bradley JS, et al. Clinical practice guidelines by the Infectious Diseases Society of America: 2018 update on diagnosis, treatment, chemoprophylaxis, and institutional outbreak management of seasonal influenza. Clin Infect Dis 2019; 68(6):e1e47. doi:10.1093/cid/ciy866

11. Beaird OE, Freifeld A, Ison MG, et al. Current practices for treatment of respiratory syncytial virus and other non-influenza respiratory viruses in high-risk patient populations: a survey of institutions in the Midwestern Respiratory Virus Collaborative. Transpl Infect Dis 2016; 18(2):210-215. doi:10.1111/tid.12510

12. Beigel JH, Nam HH, Adams PL, et al. Advances in respiratory virus therapeutics - a meeting report from the 6th Isirv Antiviral Group conference. Antiviral Res 2019; 167:45- 67. doi:10.1016/j.antiviral.2019.04.006

13. Ruan Q, Yang K, Wang W, Jiang L, Song J. Clinical predictors of mortality due to COVID-19 based on an analysis of data of 150 patients from Wuhan, China. Intensive Care Med 2020; Mar 3. doi:10.1007/s00134-020-05991-X

14. Yang $X, Y u Y, X u$ J, et al. Clinical course and outcomes of critically ill patients with SARS-CoV-2 pneumonia in Wuhan, China: a single-centered, retrospective, observational study. Lancet Respir Med 2020. doi:10.1016/S2213-2600(20)30079-5

15. Huang C, Wang Y, Li X, et al. Clinical features of patients infected with 2019 novel coronavirus in Wuhan, China. Lancet 2020; 395(10223):497- 506. doi:10.1016/S0140-6736(20)30183-5

16. Lippi G, Plebani M. Procalcitonin in patients with severe coronavi- 


\section{WU AND COLLEAGUES}

rus disease 2019 (COVID-19): a meta-analysis. Clin Chim Acta 2020; 505:190-191. doi:10.1016/j.cca.2020.03.004

17. Rule JA, Hynan LS, Attar N, et al. Procalcitonin identifies cell injury, not bacterial infection, in acute liver failure. PLoS One 2015; 10(9):e0138566. doi:10.1371/journal.pone.0138566

18. Metlay JP, Waterer GW, Long AC, et al. Diagnosis and treatment of adults with community-acquired pneumonia. An official clinical practice guideline of the American Thoracic Society and Infectious Diseases Society of America. Am J Respir Crit Care Med 2019; 200(7):e45-e67. doi:10.1164/rccm.201908-1581ST

19. Xu X, Han M, Li T, et al. Effective treatment of severe COVID-19 patients with tocilizumab. Accessed April 24, 2020. http://www. chinaxiv.org/abs/202003.00026.

20. Bloomfield M, Parackova Z, Cabelova T, et al. Anti-IL6 autoantibodies in an infant with CRP-less septic shock. Front Immunol 2019; 10:2629. doi:10.3389/fimmu.2019.02629

21. Gaensbauer JT, Press CA, Hollister JR, Asturias EJ. Procalcitonin: a marker of infection not subverted by treatment with interleukin-6 receptor inhibition. Pediatr Infect Dis J 2013; 32(9):1040. doi:10.1097/ INF.0b013e318295a3d0

22. Sato H, Tanabe N, Murasawa A, et al. Procalcitonin is a specific marker for detecting bacterial infection in patients with rheumatoid arthritis. J Rheumatol 2012; 39(8):1517-1523. doi:10.3899/jrheum.111601

23. Luo P, Liu Y, Qiu L, Liu X, Liu D, Li J. Tocilizumab treatment in COVID-19: a single center experience. J Med Virol 2020; Apr 6. doi:10.1002/jmv.25801

24. Michot JM, Albiges L, Chaput N, et al. Tocilizumab, an anti-IL6 receptor antibody, to treat COVID-19-related respiratory failure: a case report. Ann Oncol 2020; 31(7):961-964. doi:10.1016/j.annonc.2020.03.300

25. Wong HYF, Lam HYS, Fong AH, et al. Frequency and distribution of chest radiographic findings in COVID-19 positive patients. Radiology 2020; 296(2):E72-E78. doi:10.1148/radiol.2020201160

26. Kanne JP, Little BP, Chung JH, Elicker BM, Ketai LH. Essentials for radiologists on COVID-19: an update-radiology scientific expert panel. Radiology 2020; 296(2):E113-E114. doi:10.1148/radiol.2020200527

27. Pan F, Ye T, Sun P, et al. Time course of lung changes at chest CT during recovery from coronavirus disease 2019. Radiology 2020; 295(3):715-721. doi:10.1148/radiol.2020200370

28. Giamarellos-Bourboulis EJ, Mega A, Grecka P, et al. Procalcitonin: a marker to clearly differentiate systemic inflammatory response syndrome and sepsis in the critically ill patient? Intensive Care Med 2002; 28(9):1351-1356. doi:10.1007/s00134-002-1398-z

29. Wee LE, Ko KKK, Ho WQ, Kwek GTC, Tan TT, Wijaya L. Communityacquired viral respiratory infections amongst hospitalized inpatients during a COVID-19 outbreak in Singapore: co-infection and clinical outcomes. J Clin Virol 2020 Jul; 128:104436. doi:10.1016/j.jcv.2020.104436

30. Hui L, Zhang X, An X, et al. Higher serum procalcitonin and IL-6 levels predict worse diagnosis for acute respiratory distress syndrome patients with multiple organ dysfunction. Int J Clin Exp Pathol 2017; 10(7):7401-7407. pmid:31966582

31. Kalil AC, Metersky ML, Klompas M, et al. Management of adults with hospital-acquired and ventilator-associated pneumonia: 2016 clinical practice guidelines by the Infectious Diseases Society of
America and the American Thoracic Society. Clin Infect Dis 2016; 63(5):e61-e111. doi:10.1093/cid/ciw353.e111

32. Lam SW, Bauer SR, Fowler R, Duggal A. Systematic review and metaanalysis of procalcitonin-guidance versus usual care for antimicrobial management in critically ill patients: focus on subgroups based on antibiotic initiation, cessation, or mixed strategies. Crit Care Med 2018; 46(5):684-690. doi:10.1097/CCM.0000000000002953

33. Campbell L, Chen C, Bhagat SS, Parker RA, Östör AJ. Risk of adverse events including serious infections in rheumatoid arthritis patients treated with tocilizumab: a systematic literature review and metaanalysis of randomized controlled trials. Rheumatology (Oxford) 2011; 50(3):552-562. doi:10.1093/rheumatology/keq343

34. Chiu YM, Chen DY. Infection risk in patients undergoing treatment for inflammatory arthritis: non-biologics versus biologics. Expert Rev Clin Immunol 2020; 16(2):207-228. doi:10.1080/1744666X.2019.1705785

35. Yamamoto K, Goto H, Hirao K, et al. Longterm safety of tocilizumab: results from 3 years of followup postmarketing surveillance of 5,573 patients with rheumatoid arthritis in Japan. J Rheumatol 2015; 42(8):1368-1375. doi:10.3899/jrheum.141210

36. Calderón-Goercke M, Loricera J, Aldasoro V, et al. Tocilizumab in giant cell arteritis. Observational, open-label multicenter study of 134 patients in clinical practice. Semin Arthritis Rheum 2019; 49(1):126135. doi:10.1016/j.semarthrit.2019.01.003

37. Nguyen MT, Pødenphant J, Ravn P. Three cases of severely disseminated Staphylococcus aureus infection in patients treated with tocilizumab. BMJ Case Rep 2013 Jan 2;2013:bcr2012007413. doi:10.1136/bcr-2012-007413

38. Bari SF, Khan A, Lawson T. C reactive protein may not be reliable as a marker of severe bacterial infection in patients receiving tocilizumab. BMJ Case Rep 2013; Oct 31. doi:10.1136/bcr-2013-010423

39. Vanderbeke L, Spriet I, Breynaert C, Rijnders BJ, Verweij PE, Wauters J. Invasive pulmonary aspergillosis complicating severe influenza: epidemiology, diagnosis and treatment. Curr Opin Infect Dis 2018; 31(6):471-480. doi:10.1097/QCO.0000000000000504

40. Schauwvlieghe AFAD, Rijnders BJA, Philips N, et al. Invasive aspergillosis in patients admitted to the intensive care unit with severe influenza: a retrospective cohort study. Lancet Respir Med 2018; 6(10):782-792. doi:10.1016/S2213-2600(18)30274-1

41. Yu Z, Zhang Q, Gu B, et al. Clinical features of fatal pandemic influenza $\mathrm{A} / \mathrm{H} 1 \mathrm{~N} 1$ infection complicated by invasive pulmonary fungal infection. Mycopathologia 2020; 185(2):319-329. doi:10.1007/s11046-019-00421-z

42. Hwang DM, Chamberlain DW, Poutanen SM, Low DE, Asa SL, Butany J. Pulmonary pathology of severe acute respiratory syndrome in Toronto. Mod Pathol 2005; 18(1):1-10. doi: $10.1038 / \mathrm{modpathol} .3800247$

43. Koehler P, Cornely OA, Bottiger BW, et al. COVID-19 associated pulmonary aspergillosis. Mycoses 2020; 63(6):528-534. doi:10.1111/myc. 13096

Address: Kristin Highland, MD, Department of Pulmonary Medicine, A90, Cleveland Clinic, 9500 Euclid Avenue, Cleveland, $\mathrm{OH} 44195$; highlank@ccf.org 